\title{
Evaluation of Left ventricular systolic function by Myocardial Deformation Imaging in Hypertensive patients with Preserved Left Ventricular Ejection Fraction
}

\author{
Bishow Raj Baral ${ }^{1}$, Arun Maskey ${ }^{2}$, Rabi Malla ${ }^{2}$, Sujeeb Rajbhandari ${ }^{2}$, Krishna Chandra Adhikari', \\ Shreya Bhandari ${ }^{2}$, Shipra Shrestha ${ }^{2}$, Rabindra Pandey ${ }^{2}$, Rabindra shimkhada ${ }^{2}$, Arjun Budhathoki ${ }^{1}$ \\ ${ }^{1}$ Department of Cardiology, National Academy of Medical Sciences, Bir hospital, Kathmandu, Nepal \\ ${ }^{2}$ Department of Cardiology, Shahid Gangalal National Heart Centre, Kathmandu, Nepal
}

Corresponding Author: Bishow Raj Baral

Department of Cardiology, National Academy of Medical Sciences

Bir hospital, Kathmandu, Nepal

Email: bishowrajbaral@yahoo.com

ORCID ID NO: 0000-0001-9475-605X

Cite this article as: Baral B R., Maskey A., Malla R et al. Evaluation of Left ventricular systolic function by Myocardial Deformation Imaging in Hypertensive patients with Preserved Left Ventricular Ejection Fraction. Nepalese Heart Journal 2021; Vol 18(2), 15-19.

Submission date: $25^{\text {th }}$ June, 2021

Accepted date: $20^{\text {th }}$ September, 2021

\section{Abstract}

Background and Aims: Hypertension being one of the commonest non communicable diseases is major risk factor leading to premature death. With development of, the left ventricular strain imaging technique by echocardiography the consequences of hypertension may be identified and intervene earlier. The aim of study was to show abnormalities in cardiac function in the form of left ventricular strain imaging in hypertensive patients with preserved Ejection fraction.

Methods: Thi was a cross-sectional, comparative and observational study done in Shahid Gangalal National Heart Centre and National Academy of Medical Sciences, Bir Hospital Kathmandu which included hypertensive patients with baseline examination including a medical history, clinical examination and a standardized trans thoracic echocardiography and strain imaging examination and the findings were compared among age and sex frequency matched 82 healthy adults in $1: 2$ ratio. The independent paired $t$ test was used for the comparative statistical analysis.

Results: We enrolled 240 patients in this study, 158 were hypertensive (mean age $48.5 \pm 6.1$ years with $50.6 \%$ female) and 82 healthy control (mean age $45.62 \pm 6.3$ years with $51.2 \%$ female). There was no significant difference in conventional echocardiographic parameters between two groups except for left ventricular mass index and relative wall thickness that was highest in hypertensive group ( $\mathrm{p}$ value of $<0.001$ ). The hypertensive population has lower mean global longitudinal strain (GLS) value of $-18.6 \% \pm 2.06 \mathrm{SD}$ compared to the healthy control population with mean of $-19.5 \% \pm 1.1 \mathrm{SD}$ ( $\mathrm{p}$ value of $<0.001)$.

Conclusion: Hypertensive patients with preserved left ventricular ejection fraction have subclinical left ventricular dysfunction revealed by GLS imaging technique.

Keywords: Global Longitudinal strain, Hypertensive patients, left ventricular ejection fraction

DOI: https://doi.org/10.3126/njh.v18i2.40395

\section{Introduction}

Hypertension is the commonest non communicable diseases which is major risk factor leading to premature death ${ }^{1}$. Hypertension is defined as office SBP values $\geq 140 \mathrm{mmHg}$ and/or diastolic BP (DBP) values $\geq 90 \mathrm{mmHg}^{2}$. Approximately $25 \%$ to $50 \%$ of affected individuals have evidence of left ventricular (LV) hypertrophy (LVH). Left ventricular hypertrophy in systemic hypertension is a risk factor for asymptomatic left ventricular (LV) dysfunction and congestive heart failure ${ }^{3}$. While conventional echocardiography can detect changes in LV diastolic dysfunction associated with LVH, global LV systolic function often remains preserved until late in the course of the disease, which can be missed in the early stages ${ }^{4}$. Therefore, subclinical changes in LV systolic function can be identified by quantifying myocardial strain. Two-dimensional speckle tracking is a novel echocardiographic technique for analysis of LV strains ${ }^{5}$.
Strain and Strain Rate Imaging (Deformation analysis) is analysis of ventricular mechanics or shape during the cardiac cycle. Strain is defined as the normalized change in length between two points. Negative strain implies shortening of a segment (contraction) and positive strain lengthening of a segment(relaxation). As such, normal contraction is defined by negative longitudinal systolic strain $^{6}$. GLS value less than $-18 \%$ was considered abnormal for detecting LV systolic dysfunction and a value above $-20 \%$ with a standard deviation of $\sim \pm 2 \%$, is normal ${ }^{7}$. Strain analysis may detect subclinical cardiac changes in hypertensive and thus identify asymptomatic at higher risk of developing adverse changes ${ }^{8}$. Though global ejection fraction and fractional shortening are normal in hypertensive, the results showed that speckle tracking is able to detect sub-clinical myocardial dysfunction in hypertensive patients 9 .

There are only few studies found around globe about GLS imaging. GLS imaging help to find early LV systolic dysfunction 
in asymptomatic hypertensive patients ${ }^{2}$. Hypertensive patients may have evidence of left ventricular hypertrophy which is a risk factor for asymptomatic left ventricular (LV) dysfunction and congestive heart failure ${ }^{3}$. Development of congestive heart failure in hypertensive patients is worst condition. Therefore, identification of these adverse changes by GLS imaging is very important step.

The objective of this study is to assess subclinical LV systolic dysfunction in patients with systemic hypertension with preserved LV ejection fraction by GLS imaging for early detection of LV systolic dysfunction and identify those at increased risk of cardiovascular diseases in our population.

\section{Methods}

This study was a hospital based, single center cross-sectional comparative, observational study conducted in cardiology department of Shahid Gangalal National Heart Centre and National Academy of Medical Sciences, Bir Hospital Kathmandu from December 2020 to May 2020 for 6 months. Informed written consent was taken from each of the selected patient prior to enrolment in study. Formal permission for the study was taken from the institutional review board of the National Academy of Medical Sciences, Bir Hospital. Furthermore, noninvasive cardiac test such as heart rate, blood pressure, and a standardized transthoracic echocardiography and strain imaging examination was a part of the study protocol. We included 158 hypertensive patients by sample size calculation based on overall prevalence of $15.3 \%$ patients having subclinical left ventricular systolic dysfunction as assessed by global longitudinal myocardial strain in hypertensive group10. Sample size calculation was based on following equation. To compare the findings, we also included age and sex frequency matched normotensive adult population.

The Sample size is calculated by the formula $\mathrm{n} 0=\mathrm{r} /(1+\mathrm{r})(\mathrm{za} 2+\mathrm{zb} 2) \mathrm{PQ} / \mathrm{e} 2$

Where

$\mathrm{za}=1.96$ ( at $95 \%$ confidence level)

$\mathrm{zb}=0.84$ (at $80 \%$ power of test)

$\mathrm{r}($ Ratio $)=1 / 2$

$\mathrm{P}=15.3 \%$ (0.153) prevalence of subclinical left ventricular systolic dysfunction as assessed by global longitudinal myocardial strain $\mathrm{e}=(0.05) 5 \%$ of maximum tolerable error $\mathrm{Q}=100-\mathrm{P}(1-0.153)$

Study procedure: Baseline examination including a medical history, clinical examination including height, weight and body mass index were calculated. Furthermore, noninvasive cardiac test such as heart rate, blood pressure, and a standardized transthoracic echocardiography and strain imaging examination were studied. The study subjects comprise of selected patients that have fulfilled the inclusion criteria The inclusion criteria were adults age $\geq 18$ years with systemic hypertension (defined as Systolic BP $\geq 140 \mathrm{mmHg}$ and/or diastolic $\mathrm{BP} \geq 90 \mathrm{mmHg}$ or Antihypertensive treatment with a documented history of hypertension) and have an echocardiography evidence of normal LV systolic function. The exclusion criteria were Patients with coronary artery disease, cardiomyopathy, valvular heart disease, arrhythmia and conditions that affect LA size and function. We also included control group in 1: 2 case ratio with total of 82 normotensive adults which were visitors and hospital staff with age and sex frequency matched group to compare our findings.

Details of echocardiography findings were noted. Transthoracic echocardiography was performed with a commercially available imaging system with PHILLIP Affiniti 50c Echocardiography machine using a $2.5 \mathrm{MHz}$ phased array transducer. Cardiac dimension and cardiac function were measured according to the recommendations of the American Society of Echocardiography ${ }^{11}$. Global longitudinal strain (GLS) was calculated by the mean longitudinal strain of the six walls (basal, mid and apical segments) in apical view. The software automatically displayed tracing to include the entire myocardial width, and was later adjusted manually for optimal delineating. GLS value above $-20 \%$ with a standard deviation of $\sim \pm 2 \%$, is likely to be normal and less than $-18 \%$ was considered abnormal for detecting LV systolic dysfunction as given by the American Society of Echocardiography12. After 2weeks on stored offline images of 25 random study population the intraobserver reproducibility was determined by an author's own analysis and inter-observer reproducibility was done by the analyses of two other echocardiographers for strain imaging.

Statistical analysis: All the data were entered into spreadsheet of Microsoft Excel and by using SPSS version 20 software, the statistical analysis was done. Dichotomous variable with normal distribution presented as mean $\pm \mathrm{SD}$ and categorical variables were analyzed as percentage. After processing of all available information, statistical analysis of their significance was done. Dichotomous variable was compared using Chi-Square test as appropriate and independent paired t test for means of continuous variable. Odds ratio was calculated to see association between variables. Coefficient of variation analysis were performed for intra- and inter-observer reproducibility of strain imaging. For the purpose of this study a $95 \%$ confidence interval was accepted and a $p$ value $<0.05$ was taken as significant.

\section{Results}

The study population consisted of 240 subjects, including 158 patients of systemic hypertension ( $48.5 \pm 6$ years, 78 male) and 80 age- and sex-matched healthy controls ( $45.6 \pm 6.3$ years, 40 male). Clinical and demographic data of patients with systemic hypertension and controls are listed in Table 1 . There was a significant higher systolic and diastolic blood pressure in patients with systemic hypertension than the control group $(\mathrm{P}<0.001)$.

Table 1: Demographic and Baseline characteristics of study population

\begin{tabular}{|l|l|l|l|}
\hline Age(years) & Control (82) & $\begin{array}{l}\text { Hypertensive } \\
\text { Group (158) }\end{array}$ & p-value \\
\hline$<=40$ & $17(51.5 \%)$ & $16(48.5 \%)$ & 0.096 \\
\hline $41-50$ & $48(34 \%)$ & $93(66 \%)$ & \\
\hline $51-60$ & $15(25.9 \%)$ & $43(74.1 \%)$ & \\
\hline $61+$ & $2(25 \%)$ & $6(75 \%)$ & \\
\hline Mean Age & $45.62 \pm 6.3$ & $48.57 \pm 6.19$ & \\
\hline Sex & & & \\
\hline F & $42(34.4 \%)$ & $80(65.6 \%)$ & 0.931 \\
\hline M & $40(33.9 \%)$ & $78(66.1 \%)$ & \\
\hline BMI & & & \\
\hline Normal & $23(32.9 \%)$ & $47(67.1 \%)$ & 0.762 \\
\hline over weight & $26(32.1 \%)$ & $55(67.90 \%)$ & \\
\hline Obese & $33(37.1 \%)$ & $56(62.9 \%)$ & \\
\hline Risk Factors & & & \\
\hline Smoking & $15(23.8 \%)$ & $48(76.2 \%)$ & 0.044 \\
\hline DM & $14(25.9 \%)$ & $40(74.1 \%)$ & 0.147 \\
\hline Dyslipedemia & $6(18.2 \%)$ & $27(81.8 \%)$ & 0.037 \\
\hline $\begin{array}{l}\text { Family H/o } \\
\text { HTN }\end{array}$ & $6(20.7 \%)$ & $23(79.3 \%)$ & 0.103 \\
\hline Alcohol & $14(37.8 \%)$ & $23(62.2 \%)$ & 0.609 \\
\hline
\end{tabular}


Conventional echocardiography: Conventional echocardiographic data of patients with systemic hypertension and controls are listed in Table 2, which revealed significantly higher Posterior wall thickness and Relative wall thickness in hypertensive patient $(\mathrm{P}<0.001)$. Also, the Left ventricular mass index was significantly higher in the hypertensive group. There was no significant difference in the global LV ejection fraction (LVEF) between the two groups.

Table 2: Echocardiography parameters found in patients

\begin{tabular}{|l|l|l|l|l|l|}
\hline & \multicolumn{2}{|c|}{ Control (82) } & \multicolumn{2}{|c|}{$\begin{array}{l}\text { Hypertensive } \\
\text { Group (158) }\end{array}$} & p-value \\
\hline & Mean & SD & Mean & SD & pD \\
\hline $\begin{array}{l}\text { ECHO-LV } \\
\text { mass (gm) }\end{array}$ & 130.80 & 12.59 & 134.89 & 18.50 & 0.074 \\
\hline $\begin{array}{l}\text { ECHO- LV } \\
\text { Index (gm/m2) }\end{array}$ & 76.53 & 6.45 & 79.28 & 9.16 & $\mathbf{0 . 0 1 6}$ \\
\hline $\begin{array}{l}\text { ECHO- } \\
\text { Septal Wall } \\
\text { Thickness(cm) }\end{array}$ & 0.83 & 0.11 & 0.88 & 0.16 & $\mathbf{0 . 0 0 9}$ \\
\hline $\begin{array}{l}\text { ECHO- } \\
\text { LVEDD(cm) }\end{array}$ & 4.58 & 0.27 & 4.44 & 0.36 & $\mathbf{0 . 0 0 3}$ \\
\hline $\begin{array}{l}\text { ECHO- } \\
\text { PWT(cm) }\end{array}$ & 0.82 & 0.12 & 0.88 & 0.17 & $\mathbf{0 . 0 0 5}$ \\
\hline $\begin{array}{l}\text { ECHO- } \\
\text { LViSD(cm) }\end{array}$ & 2.68 & 0.24 & 2.57 & 0.28 & $\mathbf{0 . 0 0 3}$ \\
\hline $\begin{array}{l}\text { ECHO- } \\
\text { EDV(ml) }\end{array}$ & 101.59 & 15.21 & 94.62 & 18.21 & $\mathbf{0 . 0 0 3}$ \\
\hline $\begin{array}{l}\text { ECHO- } \\
\text { ESV(ml) }\end{array}$ & 28.38 & 5.97 & 25.88 & 6.56 & $\mathbf{0 . 0 0 4}$ \\
\hline $\begin{array}{l}\text { ECHO-SV(ml) } \\
\text { ECHO-FS (\%) }\end{array}$ & 72.05 & 13.93 & 68.11 & 15.70 & 0.057 \\
\hline $\begin{array}{l}\text { ECHO-EF (\%) } \\
\text { ECHO-RWT }\end{array}$ & 71.28 & 5.40 & 41.49 & 5.58 & 0.423 \\
\hline & 0.04 & 72.10 & 6.28 & 0.329 \\
\hline
\end{tabular}

2D speckle tracking: In comparison with normal controls, GLS was significantly attenuated in patients with systemic hypertension $(-19.5 .75 \pm 1.1$ in the control group vs. $-18.6 \pm 2.06$ in the hypertensive group) as shown in Table 3. We found that 54 of 158 patients $(34.2 \%)$ in the hypertensive group had subclinical LV systolic dysfunction defined as GLS less negative than $-18 \%$, but only 1 of 82 controls $(1.2 \%)$ had subclinical LV dysfunction as listed in Table 4.

Table 3: Mean GLS between two groups.

\begin{tabular}{|l|l|l|l|l|}
\hline & Number & Mean & $\begin{array}{l}\text { Std. } \\
\text { Deviation }\end{array}$ & p-value \\
\hline $\begin{array}{l}\text { Control Group } \\
\text { Hypertesive }\end{array}$ & 82 & 19.5451 & 1.10209 & $<0.001$ \\
\hline Group & 158 & 18.6392 & 2.06961 & \\
\hline
\end{tabular}

Table 4: Comparison of GLS between two groups.

\begin{tabular}{|l|l|l|l|l|}
\hline & $\begin{array}{l}\text { Reduced } \\
\text { GLS }\end{array}$ & $\begin{array}{l}\text { Normal } \\
\text { GLS }\end{array}$ & p-value & Odds(95\%CI) \\
\hline Control & $1(1.2)$ & $81(98.8)$ & $<\mathbf{0 . 0 0 1}$ & 1 \\
\hline $\begin{array}{l}\text { Hypertesive } \\
\text { Group }\end{array}$ & $54(34.2)$ & $104(65.8)$ & & $\begin{array}{l}42.06(5.70- \\
310.54)\end{array}$ \\
\hline
\end{tabular}

There was no significant difference between hypertensive patients with normal GLS and hypertensive patients with reduced GLS (subclinical LV systolic dysfunction) in terms of age and sex distribution or duration of hypertension. BMI was significantly higher among patients with reduced GLS than those with normal GLS $(\mathrm{P}<0.003)$ as listed in Table 5. Relative wall thickness (RWT), posterior wall thickness (PWT), left ventricular mass index (LVMI), and septal wall thickness (SWT) were statistically significant higher among hypertensive patients with reduced GLS than those with normal GLS. However fractional shortening (FS) and Global ejection fraction was normal in both groups as listed in Table 6 .

Table 5: Risk Factors found in two GLS Groups

\begin{tabular}{|c|c|c|c|c|c|}
\hline & \multicolumn{4}{|l|}{ GLS } \\
\hline & & $\begin{array}{l}\text { Reduced } \\
\text { GLS }\end{array}$ & $\begin{array}{c}\text { Normal } \\
\text { GLS }\end{array}$ & p-value & $\begin{array}{l}\text { Odds } \\
(95 \% \mathrm{CI})\end{array}$ \\
\hline \multirow{4}{*}{$\begin{array}{c}\text { Age } \\
\text { (years) }\end{array}$} & $<=40$ & $4(12.1)$ & $29(87.9)$ & \multirow{4}{*}{0.129} & $\begin{array}{c}0.28 \\
(0.09-0.92)\end{array}$ \\
\hline & $41-50$ & $30(21.3)$ & $111(78.7)$ & & $\begin{array}{c}0.55 \\
(0.28-1.10)\end{array}$ \\
\hline & $51-60$ & $19(32.8)$ & $39(67.2)$ & & 1 \\
\hline & $61+$ & $2(25)$ & $6(75)$ & & $\begin{array}{c}0.68 \\
(0.13-3.71)\end{array}$ \\
\hline \multirow[t]{2}{*}{ Sex } & $\mathrm{F}$ & $25(20.5)$ & 97 (79.5) & \multirow{2}{*}{0.363} & $\begin{array}{c}0.06 \\
(0.01-0.26)\end{array}$ \\
\hline & M & $30(25.4)$ & 88 (74.6) & & 1 \\
\hline \multirow[t]{2}{*}{ DM } & $\mathrm{N}$ & $41(22)$ & 145(78) & \multirow[t]{2}{*}{0.550} & $\begin{array}{c}0.81 \\
(0.40-1.63)\end{array}$ \\
\hline & Y & $14(25.9)$ & $40(74.1)$ & & 1 \\
\hline \multirow[t]{2}{*}{ Dyslipedemia } & $\mathrm{N}$ & 44 (21.3) & $163(78.7)$ & \multirow[t]{2}{*}{0.125} & $\begin{array}{c}0.54 \\
(0.24-1.20)\end{array}$ \\
\hline & Y & 11(33.3) & $22(66.7)$ & & 1 \\
\hline \multirow{3}{*}{ BMI } & normal & $6(8.6)$ & $64(91.4)$ & \multirow{3}{*}{0.003} & 1 \\
\hline & $\begin{array}{c}\text { over } \\
\text { weight }\end{array}$ & $25(30.9)$ & $56(69.1)$ & & $\begin{array}{c}4.57 \\
(1.74-11.98)\end{array}$ \\
\hline & Obese & $24(27)$ & $65(73)$ & & $\begin{array}{c}4.64 \\
(1.77-12.17)\end{array}$ \\
\hline
\end{tabular}


Table 6: Echocardiography parameters found in two GLS Groups

\begin{tabular}{|c|c|c|c|c|c|}
\hline & \multicolumn{2}{|c|}{$\begin{array}{l}\text { Reduced GLS } \\
(\mathrm{n}=55)\end{array}$} & \multicolumn{2}{|c|}{$\begin{array}{l}\text { Normal GLS } \\
(\mathrm{n}=185)\end{array}$} & \multirow[b]{2}{*}{$\mathrm{p}$-value } \\
\hline & Mean & SD & Mean & SD & \\
\hline $\begin{array}{l}\text { ECHO-LV } \\
\text { mass(gm) }\end{array}$ & 144.55 & 19.68 & 130.20 & 14.34 & $<0.001$ \\
\hline $\begin{array}{l}\text { ECHO- LV } \\
\text { Index }(\mathrm{gm} / \mathrm{m} 2)\end{array}$ & 83.43 & 10.17 & 76.83 & 7.19 & $<0.001$ \\
\hline $\begin{array}{l}\text { ECHO- } \\
\text { SWT(cm) }\end{array}$ & 0.97 & 0.17 & 0.83 & 0.12 & $<0.001$ \\
\hline $\begin{array}{l}\text { ECHO- } \\
\text { LVEDD(cm) }\end{array}$ & 4.29 & 0.38 & 4.55 & 0.30 & $<0.001$ \\
\hline $\begin{array}{l}\text { ECHO- } \\
\text { PWT(cm) }\end{array}$ & 0.96 & 0.18 & 0.83 & 0.13 & $<0.001$ \\
\hline $\begin{array}{l}\text { ECHO- } \\
\text { LViSD }(\mathrm{cm})\end{array}$ & 2.51 & 0.34 & 2.64 & 0.24 & 0.002 \\
\hline $\begin{array}{l}\text { ECHO-EDV } \\
(\mathrm{ml})\end{array}$ & 87.28 & 18.98 & 99.89 & 16.02 & $<0.001$ \\
\hline $\begin{array}{l}\text { ECHO-ESV } \\
(\mathrm{ml})\end{array}$ & 24.63 & 7.78 & 27.36 & 5.90 & 0.006 \\
\hline ECHO-SV (ml) & 62.11 & 13.54 & 71.64 & 15.01 & $<0.001$ \\
\hline ECHO-FS (\%) & 41.05 & 5.09 & 41.35 & 5.64 & 0.722 \\
\hline ECHO-EF (\%) & 71.79 & 5.91 & 71.83 & 6.30 & 0.970 \\
\hline ECHO-RWT & 0.46 & 0.12 & 0.36 & 0.08 & $<0.001$ \\
\hline $\mathrm{BSA}(\mathrm{m} 2)$ & 1.73 & 0.06 & 1.69 & 0.08 & 0.005 \\
\hline
\end{tabular}

Intra-observer and inter-observer coefficients of variation were $<$ $10 \%$ in strain imaging echocardiography.

\section{Discussion}

In systemic hypertension the development of left ventricular hypertrophy $(\mathrm{LVH})$ is an established risk factor for the development of asymptomatic left ventricular (LV) dysfunction and congestive heart failure. ${ }^{3}$ while conventional echocardiography can detect changes in LV diastolic dysfunction, global LV systolic function often remains preserved until late, making subtle changes in LV contractile function difficult to interpret in the early stages. In hypertensive subjects with normal LVEF, GLS reduction is observed independent of LV hypertrophy and diastolic dysfunction and it confers elevated cardiovascular risk ${ }^{13}$.

The above study demonstrated that $2 \mathrm{D}$ speckle tracking is able to detect sub-clinical myocardial dysfunction in hypertensive patients with normal global ejection fraction.

In our study we found that, GLS was significantly reduced in patients with systemic hypertension compared with normal controls. We also found that $34.2 \%$ of hypertensive patients had subclinical systolic LV dysfunction defined as 2D derived GLS less negative than $-18 \%$. The findings are in concordance with the study done by Imbalzano et al, who showed that 2D-STE showed an impairment of systolic longitudinal strain in all hypertensive patients including those without $\mathrm{LVH}^{14}$. Hypertension and $\mathrm{LVH}$ are important risk factors for developing chronic congestive heart failure and the mortality risk is still significantly increased over control patients ${ }^{15}$.

The finding of LV systolic longitudinal contraction by 2D speckle tracking suggest new approach in myocardial function in hypertension. This will help to identify patients at high risk who would benefit from treatment. In our study, LVMI was higher in hypertensive patients with subclinical LV systolic dysfunction (reduced GLS) than hypertensive patients with normal GLS, however the finding was not statistically significant. This finding was similar to finding of a study done by Saghir et al who revealed that hypertensive individuals with LVH had significantly decreased systolic longitudinal strain and strain rate values compared with control subjects ${ }^{16}$.

In our study, we found that hypertensive patients had higher BMI and higher LVMI than normal subjects. This finding was in consistent with the study done by Lavie et al who reported that HTN occurs in nearly $50 \%$ of obese patients and more so in class III obesity $(35<$ BMI $<40)^{17}$. However in our study we did not find any significant association of reduced GLS with cardiovascular risk and BMI. It was in contrast with the study finding of Schillaci et al who showed that there is a relationship between increased LV mass and cardiovascular risk in primary hypertension, even in the absence of hypertensive mediated organ damage ${ }^{18}$. Similarly the result of this study was in contrast with the study done by A.M. Ayoub et al, who reported that with regard to the effect of BMI on GLS, increasing BMI showed a greater likelihood of developing subclinical LV dysfunction ${ }^{19}$.

We excluded patients older than 60 years on myocardial contractility function and hence affecting GLS to avoid aging effect in this study. Aging effect was seen in the study done by Fernandes et al where he showed that patients with subclinical atherosclerosis presented with greater carotid intima media thickness has associated alternations of myocardial strain parameters ${ }^{20}$.We also found that $1.2 \%$ of healthy individuals had subclinical LV dysfunction, and we attribute this to smoking, ${ }^{21}$ or atherosclerosis.

\section{Limitation}

The study was hospital based and general population was not included. It is limited by small sample size. Also, radial and circumferential strain have not been discussed. The operator was not double blinded about hypertensive patients and control subjects. However, this study is preliminary and provides a base for future larger studies. Hence larger randomized population would more likely reflect the true pictures.

\section{Conclusion}

Detecting subclinical LV dysfunction in systemic hypertension by GLS imaging technique is an important tool which is not noticed by conventional echocardiography. Therefore it is better to use these technique in systemic hypertension patients for early detection of subclinical LV dysfunction. We concluded that 2D-STE detected subclinical LV systolic dysfunction in $34.2 \%$ of our patients with systemic hypertension (patients with GLS less negative than $-18 \%$ ), despite preserved LVEF and independent LV structural changes. This suggests that detecting subclinical LV dysfunction in systemic hypertension by GLS imaging technique is an important tool for early management of hypertensive individuals for prevention of future events.

\section{Acknowledgment}

The author acknowledges the Cardiology department of Shahid Gangalal National Heart Centre and National Academy of Medical Sciences, Bir Hospital Kathmandu

\section{Conflict of interest:}

None

\section{References}

1. WHO. World Health Organization, World Health Statistics 2012. Geneva: World Health Organization, 2012.

2. Bryan Williams, Giuseppe Mancia, Wilko Spiering et al, $2018 \mathrm{ESC} / \mathrm{ESH}$ Guidelines for the management of arterial hypertension: The Task Force for the management of arterial hypertension of the European Society of Cardiology (ESC) and the European Society of Hypertension (ESH). European Heart Journal, 2018;39:3021-3104. doi: 10.1093/eurheartj/ehy339. 
3. Rovner A., de las Fuentes L., Waggoner A.D., Memon N., Chohan R., Dávila-Román V.G. Characterization of left ventricular diastolic function in hypertension by use of Doppler tissue imaging and color M-mode techniques. J Am Soc Echocardiogr. 2006;19:872-879.doi: 10.1016/j. echo.2006.01.023.

4. Lorell B.H., Carabello B.A. Left ventricular hypertrophy: pathogenesis, detection, and prognosis. Circulation. 2000;102:470-479.doi: 10.1161/01.cir.102.4.470.

5. Reisner S.A., Lysyansky P., Agmon Y., Mutlak D., Lessick J., Friedman Z. Global longitudinal strain: a novel index of left ventricular systolic function. J Am Soc Echocardiography. 2004;17:630-633.doi: 10.1016/j.echo.2004.02.011.

6. William F. Armstrong, Thomas Ryan, Feigenbaum's Echocardiography Eighth edition Philadelphia : Wolters Kluwer, 2019.

7. Collier P PD, Klein A, Testin A et al: Myocardial Strain Measured by Speckle-Tracking Echocardiography. JACC 2017; 69, 1043-1056. https://doi.org/10.1016/j. jacc.2016.12.012.

8. T. Helle-Valle, J. Crosby, T. Edvardsen, et al.New noninvasive method for assessment of left ventricular rotation: speckle tracking chocardiography.Circulation, 112 (2005), pp. 3149-3156 http://dx.doi.org/10.1161/ CIRCULATIONAHA.104.531558

9. Chen J., Cao T., Duan Y., Yuan L., Wang Z. Velocity vector imaging in assessing myocardial systolic function of hypertensive patients with left ventricular hypertrophy. Can J Cardiol. 2007;23:957-961.DOI: 10.1186/s12947-015-0002-y

10. Gonçalves S, Cortez-Dias N, Nunes A, Belo A, Zimbarra Cabrita I, Sousa C, et al. Left ventricular systolic dysfunction detected by speckle tracking in hypertensive patients with preserved ejection fraction. Rev Port Cardiol. 2014;33(1):2737.https://doi.org/10.1016/j.repce.2013.07.013.

11. Mor-Avi V, Lang RM, Badano LP et al. Current and evolving echocardiographic techniques for the quantitative evaluation of cardiac mechanics: ASE/EAE consensus statement on methodology and indications endorsed by the Japanese Society of Echocardiography. J Am Soc Echocardiogr; 2011; 24:277-313.doi: 10.1016/j.echo.2011.01.015.

12. Sengupta SP, Caracciolo G, Thompson C, Abe H, Sengupta PP. Early impairment of left ventricular function in patients with systemic hypertension: new insights with 2-dimensional speckle tracking echocardiography. Indian Heart J. 2013;65:48-52. doi: 10.1016/j.ihj.2012.12.009.

13. Lee W.H., Liu Y.W., Yang L.T., Tsai W.C. (2016) Prognostic value of longitudinal strain of subepicardial myocardium in patients with hypertension. J Hypertens 34:1195-1200.doi: 10.1097/HJH.0000000000000903.

14. Imbalzano E, Zito C, Carerj S, et al. Left ventricular function in hypertension: new insight by speckle tracking echocardiography. Echocardiography. 2011;28:649-57. DOI: 10.1111/j.1540-8175.2011.01410.x

15. Aurigemma G.P., Gottdiener J.S., Shemanski L., Gardin J., Kitzman D. Predictive value of systolic and diastolic function for incident congestive heart failure in the elderly: the cardiovascular health study. J Am Coll Cardiol. 2001;37:1042-1048.DOI: 10.1016/s0735-1097(01)01110-x
16. Saghir M, Areces M, Makan M. Strain rate imaging differentiates hypertensive cardiac hypertrophy from physiologic cardiac hypertrophy (athlete's heart) J Am Soc Echocardiogr. 2007;20(2):151-7.doi: 10.1016/j. echo.2006.08.006.

17. Lavie CJ, Alpert MA, Arena R, Mehra MR, Milani RV, Ventura HO. Impact of obesity and the obesity paradox on prevalence and prognosis in heart failure. JACC Heart Fail. 2013;2:93-102.doi: 10.1016/j.jchf.2013.01.006.

18. Schillaci G, Verdecchia P, Porcellati C, et al. Continuous relation between ventricular mass and cardiovascular risk in essential hypertension. Hypertension. 2000;35:580-6.doi: 10.1161/01.hyp.35.2.580

19. Ayoub AM, Keddeas VW, Ali YA, El Okl RA. Subclinical LV Dysfunction Detection Using Speckle Tracking Echocardiography in Hypertensive Patients with Preserved LV Ejection Fraction. Clin Med Insights Cardiol. 2016;10:85-90. Published 2016 Jun 27. doi:10.4137/CMC.S38407

20. Fernandes VRS, Polak JF, Edvardsen T, et al. Subclinical atherosclerosis and incipient regional myocardial dysfunction in asymptomatic individuals. J Am Coll Cardiol. 2006;47(12):2420-8.doi: 10.1016/j.jacc.2005.12.075.

21. Rosen BD, Saad MF, Shea S, et al. Hypertension and smoking are associated with reduced regional left ventricular function in asymptomatic individuals. J Am Coll Cardiol. 2006;47(6):1150-8.doi: 10.1016/j.jacc.2005.08.078. 